\title{
EXTRATOS DE PLANTAS DE COBERTURA NO DESENVOLVIMENTO DE SCLEROTINIA SCLEROTIORUM
}

\author{
F.P. Monteiro ${ }^{1}$, L.P. Pacheco $^{2}$, E.R. Lorenzetti ${ }^{1}$, C. Armesto ${ }^{1}$, P.E. de Souza ${ }^{1}$, M.S. de Abreu ${ }^{1}$ \\ ${ }^{1}$ UniversidadeFederal de Lavras, Departamento de Fitopatologia, CP3037, CEP37200-000, Lavras, MG, Brasil.
}

\author{
RESUMO
}

\begin{abstract}
Extratos vegetais podem interferir no ciclo de vida dos fitopatógenos por promover ou inibir o desenvolvimento. Com base nessa propriedade, este trabalho foi realizado com o objetivo de estudar o efeito dos extratos aquosos das plantas de cobertura crotalária (Crotalaria juncea), braquiária (Brachiaria ruziziensis), capim-mombaça (Panicum maximum cv. mombaça), milheto (Pennisetum glaucum), feijão-guandu-anão (Cajanus cajan) e estilosantes (Stylosanthes capitata x Stylosanthes macrocephala) sobre o crescimento micelial, germinação carpogênica e micelial dos escleródios e germinação dos ascósporos do fungo Sclerotinia sclerotiorum. As etapas do experimento foram desenvolvidas em casa de vegetação, câmaras de crescimento e laboratório. As concentrações dos extratos utilizadas foram de 1\%,5\%,10\% e 25\%. Para verificar a influência dos extratos sobre a germinação micelial e carpogênica dos escleródios, foi utilizada somente a concentração de $25 \%$. Os resultados sobre o crescimento micelial mostraram que o extrato da planta de Stylosanthes sp. inibiu o desenvolvimento do patógeno apenas na concentração de $25 \%$. Para a germinação micelial dos escleródios, verificou-se que os extratos induziram a germinação 12 horas após a instalação do experimento, exceto o Stylosanthes sp. Na germinação dos ascósporos, apenas o extrato de Stylosanthes sp. impediu a germinação.
\end{abstract}

PALAVRAS-CHAVE: Mofo branco, manejo cultural, ascósporos, escleródios, apotécios.

\section{ABSTRACT}

PLANT EXTRACTS OF COVER CROPS IN THE DEVELOPMENT OF SCLEROTINIA SCLEROTIORUM. Plant extracts may interfere with the life cycle of pathogens by promoting or inhibiting development. Based on this property, the present study aimed to evaluate the effect of aqueous extracts of the cover plants crotalaria (Crotalaria juncea), brachiaria (Brachiaria ruziziensis), panicum maximum grass (Panicum maximum cv. mombaça), millet (Pennisetum glaucum), pigeon pea dwarf bean (Cajanus cajan.) and stylosanthes (Stylosanthes macrocephalax Stylosanthes capitata) on the mycelial growth, mycelial and carpogenic germination of sclerotia, and ascospore germination of Sclerotinia sclerotiorum. The stages of the experiment were carried out in a greenhouse, growth chambers and laboratory. The concentrations of the extracts used were $1 \%, 5 \%, 10 \%$ and $25 \%$. To assess the influence of extracts on the mycelial and carpogenic germination of the sclerotia only the concentration of $25 \%$ was used. The results on the mycelial growth showed that the Stylosanthes sp. plant extract was effective for inhibiting the pathogen only at concentration of $25 \%$. For mycelial germination of sclerotia, it was found that with the exception of Stylosanthes sp. the extracts induced germination 12 hours after the experiment. In regard to the germination of ascospores, only the extract from Stylosanthes sp. successfully prevented germination.

KEY WORDS: White mold, cultural management, ascospores, sclerotia, apothecium.

\section{INTRODUÇÃO}

Nos últimos anos, os produtores de soja, feijão, girassol e algodão de diversas regiões do Cerrado, nos estados de Goiás, Minas Gerais e Bahia, convivem com danos significantes em suas lavouras, em consequência do mofo-branco, doença causada pelo fungo Sclerotinia sclerotiorum (EMBRAPA, 2010).
O ciclo de vida do patógeno inicia-se com a germinação do ascósporo que, com o tempo, forma-se o micélio. À medida que este micélio se compacta, origina-se uma estrutura de resistência conhecida como escleródio. Em umidade e temperatura adequada, o escleródio produz corpos de frutificação chamados de apotécios. Nestes, existem um número variável de ascos, que liberam os ascósporos no

${ }^{2}$ Universidade Federal do Piauí, Departamento de Fitotecnia, Bom Jesus, PI, Brasil. 
ambiente para reiniciar o ciclo (PURDY, 1979). Este fungo foi relatado como patogênico a 48 famílias, 278 gêneros e 408 espécies de plantas (BOLAND; RALL, 1994). Este amplo espectro de hospedeiros é um dos fatores que dificultam o manejo do fungo.

Para tentar controlar o fungo, várias táticas têm sido empregadas, entreelas, a utilização de plantas de cobertura queliberam compostos no solo, na tentativa de diminuir o potencial de inóculo. Segundo COSTA; RAvA (2003), a rotação com Brachiaria sp. em sistema de plantio direto tem sido uma alternativa viável para o controle de patógenos que sobrevivem no solo. Pereira Neto; Blum (2010) mostraram que a adição de fitomassa de milheto ao solo reduz a podridão do colo (Sclerotium rolfsii) em feijoeiro e estimula o aumento da população natural de Pseudomonas do grupo fluorescente. Esses resultados reforçam a natureza diferencial quanto ao nicho requerido por patógeno e a capacidade de reprodução dos organismos antagonistas ao seu desenvolvimento no solo.

A população microbiológica do solo apresenta grandeimportância em estudos fitopatológicos, uma vez que o manejo pode modificar a relação entre aqueles micro-organismos considerados benéficos e maléficos ao crescimento das plantas (MARSCHENER et al., 2001). Cada espécie de planta comporta-se de maneira diferente quanto a esse estímulo, possibilitado pela liberação de nutrientes e substâncias químicas promotoras ou deletérias do crescimento em determinados grupos de micro-organismos (RochA et al., 2004).

O estudo de fatores relacionados com o solo, tal como o efeito causado pela presença de plantas de cobertura em áreas infestadas pelo fungo, érelevante, uma vez que, aproximadamente, $90 \%$ do ciclo de vida ocorrem no solo (ADAMS; AYERS, 1979; AsIRIFI et al., 1994). Durante a decomposição essas plantas liberam, de maneira gradual, compostos que influenciam o desenvolvimento do patógeno. Segundo HaO et al. (2003), resíduos de brócolis reduzem a viabilidade dos escleródios de Sclerotinia minor, efeito atribuído a glucosinolatos. A fitomassa de Chenopodium quinoa também pode reduzir a viabilidade de S. sclerotioum, pois alguns cultivares podem liberar saponinas, substâncias prejudiciais ao desenvolvimento do fungo, durante a decomposição de seus resíduos (Dubey et al., 1983).

Segundo Sonaglio et al. (2003), extratos são todos os produtos obtidos a partir de matéria-prima vegetal. Essas substâncias podem ser extraídas por meio de diferentes metodologias preparadas em meio aquoso, etanoico, hidroetanoico, oleoso, entre outros, sendo que a metodologia empregada depende do tipo de substância que se quer extrair (QueIroz et al., 2001).

A presença do extrato vegetal pode reduzir o crescimento de micro-organismos fitopatogênicos, em razão da presença de substâncias antimicrobianas. Segundo RodRIGUEs et al. (2007), o extrato bruto aquoso de gengibre inibiu o crescimento micelial e a produção de escleródios de S. sclerotiorum. Entretanto, ao empregar extratos de espécies hospedeiras, pode haver promoção no desenvolvimento, como mostraram LEANDRO et al. (2003), ao aplicarem extratos de flores e folhas de morango observaram umaumentononúmero dos conídios de Colletotrichum acutatum. Todavia, são escassos os estudos que envolvem os fatores que estão relacionados com a capacidade das plantas de cobertura utilizadas em sistema de plantio direto, em culturas anuais no cerrado, reduzir os efeitos deletérios de áreas infestadas com S. sclerotiorum.

Assim, este trabalho foi realizado com o objetivo de conhecer a influência dos extratos vegetais das plantas de cobertura utilizadas no cultivo de culturas anuais no Cerrado sobre o crescimento micelial em meio de cultura com diferentes concentrações dos extratos de plantas, germinação micelial e carpogênica dos escleródios em solo embebido com os extratos de plantas e também o efeito direto dos extratos de plantas em diferentes concentrações sobre a germinação dos ascósporos do fungo de S. sclerotiorum.

\section{MATERIAL E MÉTODOS}

O trabalho foi realizado em Lavras, MG, localizada nas coordenadas $21^{\circ} 14^{\prime} 43^{\prime \prime}$ latitude sul, $44^{\circ} 59^{\prime} 59^{\prime \prime}$ longitude oeste e altitude de $919 \mathrm{~m}$, no período de janeiro a julho de 2010, em delineamento inteiramente casualizado.

A obtenção dos escleródios de S. sclerotiorum para utilização no experimento foi induzida de maneira artificial, com a produção a partir de um único escleródio, coletado em lavouras de soja na região de Rio Verde, GO. Foi colocado um escleródio no centro da placa de Petri com meio batata-dextrose-ágar (BDA) e, em seguida, acondicionada em câmara de crescimento a $20^{\circ} \mathrm{C}$, com fotoperíodo de 12 horas, por 20 dias. Após a produção dos primeiros escleródios, discos de micélio foram transferidos para outras placas contendo o mesmo meio de cultura, para induzir a produção de mais escleródios, sendo esse procedimento repetido sucessivas vezes, até que atingisse a quantidade necessária. Todos escleródios foram desinfestados em solução de álcool a 70\%, por 30 segundos e hipoclorito de sódio a $2 \%$, por 2 minutos, seguido por três lavagens sucessivas em água destilada esterilizada. Os escleródios obtidos e desinfestados foram então, armazenados em sacos de papel em temperatura de $27^{\circ} \mathrm{C}$.

Para a obtenção dos extratos aquosos as plantas decobertura: crotalária (Crotalariajuncea), braquiária (Brachiaria ruziziensis), capim-mombaça (Panicum 
maximum cv. mombaça), milheto (Pennisetum glaucum), feijão-guandu-anão (Cajanus cajan) e estilosantes (Stylosanthes sp.) foram semeadas em Latossolo Vermelho-Escuro, em vasos com capacidade para $8 \mathrm{~kg}$, cultivadas até os 45 dias após a emergência. Atingido esse período, foram ceifadas $100 \mathrm{~g}$ defolhas e trituradas num volume de $200 \mathrm{~mL}$ deágua com um liquidificador. A mistura obtida foi filtrada, sendo submetida a um processo de esterilização com membranas antimicrobianas com porosidade de $0,22 \mu \mathrm{m}$. A partir da solução esterilizada foram preparadas diferentes concentrações $(1 \%, 5 \%, 10 \%$ e $25 \%)$, por meio de diluição em água destilada esterilizada.

O primeiro ensaio foi realizado para observar o efeito dos extratos de plantas em diferentes concentrações sobre o crescimento micelial do patógeno em meio BDA. O ensaio consistiu em adicionar os extratos ao meio de cultura BDA líquido em temperatura fundente (batata-ágar-dextrose), sendo ajustadas as concentrações em função da quantidade de meio adicionado na placa de Petri com $9 \mathrm{~mm}$ de diâmetro (volume total em cada placa foi de $20 \mathrm{~mL}$ ), visto que após esta adição foram novamente diluídas. A testemunha continha apenas o meio BDA sem adição de extratos vegetais e, para compensar a quantidade de extrato inserida nos outros tratamentos, foi adicionada água destilada esterilizada. No centro de placa de Petri foi adicionado um disco de meio de cultura BDA com $9 \mathrm{~mm}$ de diâmetro contendo micélio de $S$. sclerotiorum, previamente cultivado em meio BDA e mantido a $20^{\circ} \mathrm{C}$ e fotoperíodo de 12 horas. Essas placas foram vedadas com parafilme e acondicionadas em câmaras de crescimento, à temperatura de $20^{\circ} \mathrm{C}$ e fotoperíodo de 12 horas. Foram feitas 3 testemunhas para cada tratamento. As avaliações do crescimento micelial radial foram realizadas a cada 12 horas, totalizando 4 dias de avaliação. De posse dos dados, foi calculado o índice da velocidade de crescimento micelial (IVCM) segundo a fórmula adaptada por OliveIRA (1991): IVCM $=\Sigma(\mathrm{D}-\mathrm{Da}) / \mathrm{N}$, em que IVCM = Índice de velocidade de crescimento micelial $\left(\mathrm{cm} \cdot \mathrm{dia}^{-1}\right), \mathrm{D}=$ Diâmetro médio atual $(\mathrm{cm})$, $\mathrm{Da}=$ Diâmetro médio do dia anterior $(\mathrm{cm})$, e $\mathrm{N}=$ Número de dias após a inoculação (dias).

Em um segundo ensaio avaliou-se o tipo de germinação dos escleródios, micelial e carpogênica, bem como, a porcentagem de escleródios germinados e o número de apotécios formados, utilizaram-se caixas plásticas Gerbox, preenchidas com $200 \mathrm{~g}$ da mistura de solo e areia, esterilizada via autoclavagem, conforme metodologia descrita por MENEZES; SiLva-Hanlin (1997), na proporção de 1:1. Em cada tratamento foram adicionados $50 \mathrm{~mL}$ de cada extrato a $25 \%$, sendo adicionados ao solo 25 escleródios, previamente esterilizados, distribuídos de maneira equidistantes na superfície do solo em placa. Cada tratamento teve 3 testemunhas, onde foram aplicados
$50 \mathrm{~mL}$ de água destilada esterilizada aos invés dos extratos de plantas. Neste experimento os extratos foram preparados, separadamente, a partir de hastes e folhas das plantas de cobertura, com exceção do Stylosanthes sp., que foi obtido pela maceração de hastes e folhas para obter um único extrato. A umidade foi ajustada até a capacidade de campo pela adição de água destilada esterilizada para todos os tratamentos. A quantidade de água adicionada foi determinada pela diferença de peso entre um solo totalmente seco e um solo encharcado. Os escleródios foram imersos nos extratos por 5 minutos, em função de cada tratamento e, após esse procedimento foram dispostos dezesseis escleródios, de maneira equidistante em cada caixa. Em seguida, essas caixas foram fechadas com tampa apropriada e as laterais vedadas com parafilme. Após esse processo, foram acondicionadas em câmara de crescimento, à temperatura de $20^{\circ} \mathrm{C}$ e fotoperíodo de 12 horas por 45 dias, período suficiente para a produção de apotécio. Os escleródios foram avaliados quanto à germinação micelial aos 12 horas e 14 dias após a instalação do experimento; quanto à germinação carpogênica e o número de apotécios formados aos 30, 37, 45 e 59 dias após a instalação do experimento.

No terceiro ensaio avaliou-se a influência dos extratos vegetais sobre a germinação dos ascósporos de S. sclerotiorum. Para a produção de ascósporos foram utilizadas caixas plásticas Gerbox, preenchidas com $200 \mathrm{~g}$ da mistura de solo e areia, esterilizada via autoclavagem, conforme metodologia descrita por Menezes; Silva-Hanlin (1997), na proporção de 1:1. O solo foi umedecido com $50 \mathrm{~mL}$ de água, sendo adicionados ao solo 25 escleródios, previamente esterilizados, distribuídos de maneira equidistantes na superfície do solo. Após esse processo, foram acondicionadas em câmara de crescimento, à temperatura de $20^{\circ} \mathrm{C}$ e fotoperíodo de 12 horas por 45 dias. Após a germinação dos apotécios, cinco destas estruturas foram imersas em $10 \mathrm{~mL}$ deágua destilada estéril contida num cadinho e foram macerados com o pistilo por 3 minutos, obteve-se assim a suspensão de ascósporos. Foi utilizada a placa destinada para o teste ELISA (Enzyme-Linked Immuno Sorbent Assay), tendo cada orifício desta placa, recebido um tratamento. Foram depositados nos orifícios $100 \mu \mathrm{L}$ da suspensão de ascósporos e extratos vegetais tendo cada concentração $(1 \%, 5 \%, 10 \%$ e $25 \%)$ sido obtida por meio de diluição em água destilada esterilizada. A testemunha foi obtida inserindo $100 \mu \mathrm{L}$ de água destilada esterilizada em um dos orifícios da placa. Foram feitas 3 repetições para cada tratamento. Essa placa foi mantida em câmara de crescimento à temperatura de $20^{\circ} \mathrm{C}$ e fotoperíodo de 12 horas, por um período de 48 horas. Este mesmo procedimento foi realizado em duas etapas, sendo que, na primeira, não houve a adição denenhum antibiótico;já na segunda, 
foram adicionados $5 \mathrm{~g}$ de sulfato de streptomicina em $100 \mu \mathrm{L}$ da suspensão de ascósporos.

Para verificar o efeito direto sobre a germinação dos ascósporos, foi utilizada a objetiva de 40 vezes de um microscópio óptico, em que os primeiros 100 ascósporos visualizados foram discriminados em: germinados, quando o crescimento micelial era duas vezes o diâmetro do ascósporo ou não germinados, decorridas 24 e 48 horas da instalação do experimento. Os resultados utilizados foram a média de 4 contagens realizadas para aferir a germinação do ascósporo.

Os resultados foram submetidos à análise de variância e, quando significativa pelo teste F, as médias foram comparadas pelo teste deScott-Knott teste estatístico, através do softwareSisvar (FERREIRA, 2003).

\section{RESULTADOS E DISCUSSÃO}

Ao analisar os resultados observou-se que os extratos das plantas de cobertura interferiram no crescimento micelial do patógeno, sendo que o extrato de Styloshantes sp. conseguiu reduzir de forma substancial o crescimento do patógeno na concentração de $25 \%$. Por outro lado, os extratos de C. cajan, P. glaucum, B. ruzizienzis, P. maximum cv. mombaça e $C$. juncea promoveram acréscimos no desenvolvimento micelial fúngico, mesmo a partir da concentração de $5 \%$ (Tabela 1).

Esses resultados podem ser explicados pela possibilidade de presença de substâncias inibidoras e/ou promotoras do crescimento nos extratos de plantas de cobertura. PINTo et al. (1998) verificaram que o extrato aquoso de Crotalaria paulina inibiu o crescimento micelial de Sclerotium cepivorum em $67 \%$, $53 \%$ e $27 \%$, nas concentrações de $0,01 \%, 0,1 \%$ e $1 \%$, respectivamente.

Observou-se também que o extrato aquoso de $B$. humidicola reduziu o crescimento micelial em torno de $64 \%$ na dose de $1 \%$, sendo esse efeito atribuído à concentração de saponinas. Por outro lado, os extratos podem promover o crescimento micelial por conter substâncias nutritivas, capaz deestimularemo desenvolvimento microbiano. FrANZENER et al. (2007) observaram que o hidrolato de Cymbopogon nardus promoveu considerável estímulo ao desenvolvimento dos tubos germinativos de Alternaria brassicae.

Oextrato de Styloshantessp. apresentou resultados satisfatórios quanto a redução do índice de velocidade de crescimento micelial (IVCM), uma vez que, na concentração de $25 \%$, os valores apresentaramse próximos ao controle total do patógeno. Esses resultados reafirmam o potencial dessa espécie em apresentar compostos antifúngicos em sua fitomassa. Os extratos de $P$. glaucum, $B$. ruzizienzis, $P$. maximum cv. mombaça, $C$. juncea e C. cajan não foram eficientes na redução do crescimento micelial de S. sclerotiorum, o que pode ser atestado pelo aumento do IVCM, mesmo nas concentrações mais baixas. Isso mostra que, dependendo do estádio de desenvolvimento do fungo, a presença de extratos das plantas de cobertura na área pode aumentar o progresso da doença nas lavouras, por conter compostos promotores de crescimento do fitopatógeno. Mileo et al. (2006) mostraram que as plantas de cobertura Calopogonuim mucunioides, Crotalaria striata, Mucuna aterrima e Pueraria phaseoloides foram suscetíveis a Colletotrichum guaranicola, o que pode aumentar o potencial de inóculo do patógeno na área.

A análise de regressão das concentrações dos extratos das plantas de cobertura mostrou-se significativa apenas para o extrato oriundo da planta de cobertura Styloshantes sp., a qual obteve valores para o índice de velocidade de crescimento micelial próximos a zero na concentração de 25\% (Fig. 1), sendo quenessa concentração pode haver substâncias antagônicas suficientes para reduzir o crescimento fúngico. As demais plantas de cobertura apresentam aumento no IVCM por, possivelmente, apresentar compostos que promovem o desenvolvimento do patógeno.

Tabela 1 - Efeito dos extratos das plantas de cobertura em diferentes concentrações sobre o crescimento micelial de $S$. sclerotiorum.

\begin{tabular}{lcccc}
\hline \multirow{2}{*}{ Extrato aquoso } & \multicolumn{4}{c}{ Índice de velocidade de crescimento micelial $(\mathrm{cm})$} \\
\cline { 2 - 5 } & \multicolumn{4}{c}{ Concentração } \\
\cline { 2 - 5 } & $1 \%$ & $5 \%$ & $10 \%$ & $25 \%$ \\
\hline Styloshantes sp. & $4.7629 \mathrm{a}$ & $5.7895 \mathrm{a}$ & $5.0812 \mathrm{a}$ & $0.1500 \mathrm{a}$ \\
Pennisetum glaucum & $4.7672 \mathrm{a}$ & $8.1020 \mathrm{c}$ & $7.9479 \mathrm{~b}$ & $8.4125 \mathrm{~d}$ \\
Brachiaria ruzizienzis & $4.7678 \mathrm{a}$ & $7.4979 \mathrm{~b}$ & $7.8375 \mathrm{~b}$ & $6.5646 \mathrm{c}$ \\
Panicum maximum cv. mombaça & $4.7653 \mathrm{a}$ & $8.8020 \mathrm{c}$ & $7.2833 \mathrm{~b}$ & $7.4479 \mathrm{~d}$ \\
Crotalaria juncea & $4.9283 \mathrm{a}$ & $7.1229 \mathrm{~b}$ & $7.0145 \mathrm{~b}$ & $8.0645 \mathrm{~d}$ \\
Cajanus cajan & $4.7620 \mathrm{a}$ & $7.1166 \mathrm{~b}$ & $6.3625 \mathrm{~b}$ & $6.6958 \mathrm{c}$ \\
Testemunha & $4.7687 \mathrm{a}$ & $4.7687 \mathrm{a}$ & $4.7687 \mathrm{a}$ & $4.7687 \mathrm{~b}$ \\
\hline CV & & \multicolumn{4}{c}{14,70} &
\end{tabular}

Médias seguidas com a mesma letra minúscula na coluna não diferem entre si, pelo teste de Scott-Knott, a $5 \%$ de probabilidade. 

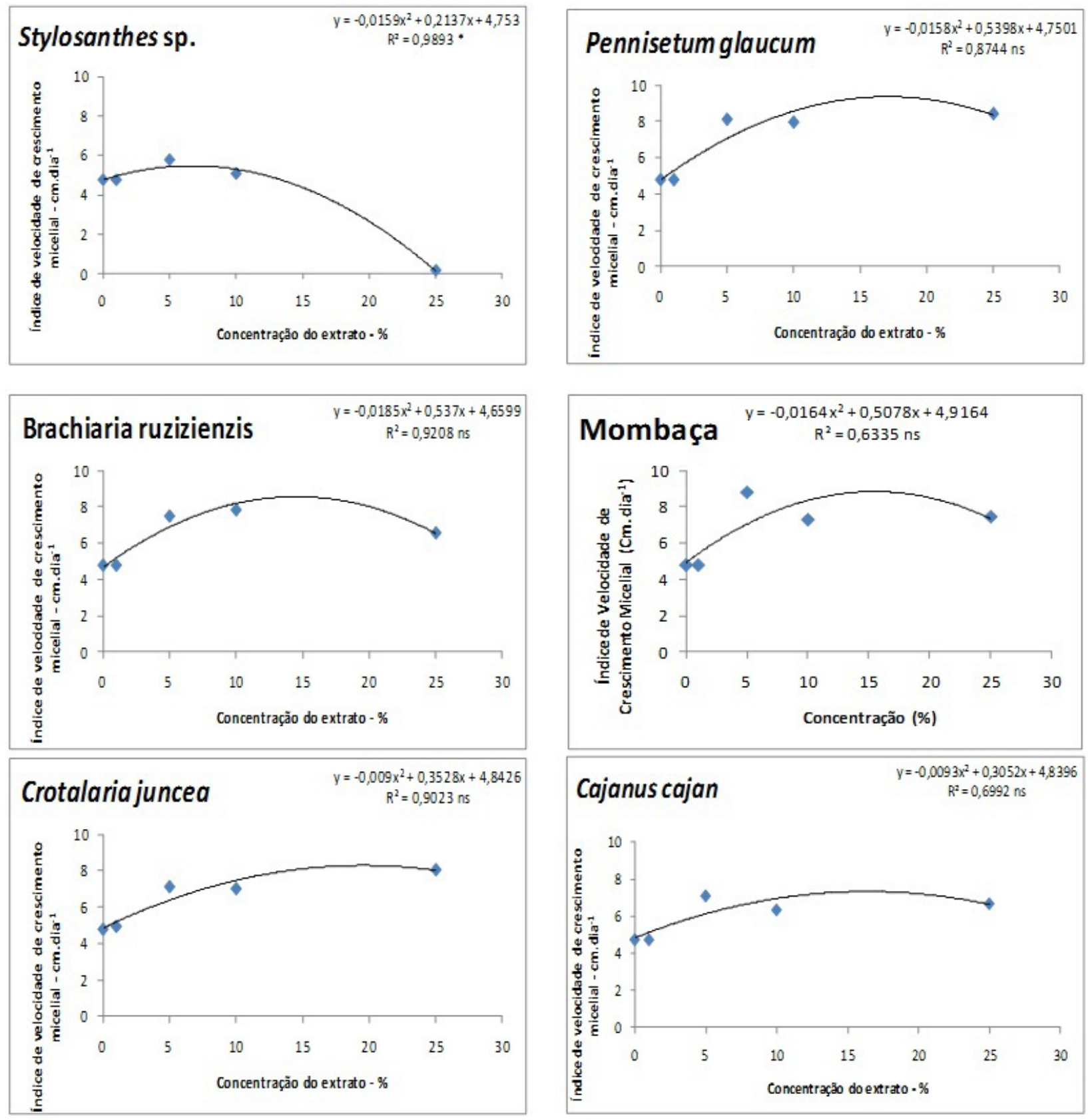

Fig. 1 - Extratos das plantas de cobertura em diferentes concentrações sobre o índice de velocidade de crescimento micelial de Sclerotinia sclerotiorum; ${ }^{\text {ns: }}$ não significativo ${ }^{*} \mathrm{p}<0,05$ significativo.

A germinação micelial dos escleródios ocorreu 12 horas após a instalação do experimento (Tabela 2). Na avaliação dos 14 dias nãohouvea germinação denovos escleródios e os valores mantiveram-se iguais aos da primeira avaliação. Observou-se elevadocrescimento micelial para todos os tratamentos, com exceção do extrato de Styloshantes sp. e testemunha. Assim, é possível afirmar que os extratos dessas plantas influenciaram o crescimento micelial dos escleródios pelo aporte adicional de nutrientes e compostos promotores de crescimento. O extrato de Styloshantes sp. não promoveu estímulos à germinação micelial dos escleródios, o que pode estar relacionado à presença de substâncias antimicroabianas e compostos nutritivos não assimiláveis ao fungo, uma vez que vários estudos já constatarem a presença de nutrientes na fitomassa dessas plantas de cobertura, como relata o trabalho de SILVEIRA et al. (2005) em que observaram quea fitomassa de Styloshantes sp. apresenta potencial de acumular $90 \mathrm{~g} \mathrm{ha}^{-1}, 12 \mathrm{~kg} \mathrm{ha}^{-1}, 60 \mathrm{~kg} \mathrm{ha}^{-1}, 60 \mathrm{~kg} \mathrm{ha}^{-1}$ e $12 \mathrm{~kg} \mathrm{ha}^{-1}$ de nitrogênio, fósforo, potássio, cálcio e magnésio, respectivamente. 
Segundo HuANG (1985), a completa formação da camada de melanização impede a imediata germinação de escleródios na falta de nutrientes fornecidos exogenamente, o que promove dormência. Então, pode-se inferir que os extratos das plantas de cobertura, com exceção do extrato de Styloshantes sp., fornecem quantidade adicional de nutrientes, o que permite uma maior germinação micelial do escleródio em poucas horas. A ocorrência da germinação micelial na testemunha pode ser explicada pela existência de nutrientes presentes na mistura solo + areia, suficientes para incitar germinação, porém pouco expressiva se comparada aos demais tratamentos. Lopes et al. (2008) apontaram a possibilidade da relação entre fertilidade do solo e incidência de Fusarium oxysporum f.sp cubense.

Com base nos resultados, o número de apotécios formados não se apresentou influenciado pela presença dos extratos das coberturas vegetais na concentração testada (Tabela 3), sendo que o efeito dessas plantas na supressão dos apotécios pode estar relacionado à fitomassa, uma vez que esta reduz a quantidade de luz que seria captada pelo escleródio necessária para sua formação (PHILLIIS, 1987).

Tabela 2 - Porcentagem de germinação micelial dos escleródios, em função dos extratos aquosos a 25\%, 12 horas e 14 dias após a instalação do experimento.

\begin{tabular}{lcc}
\hline & Germinação micelial dos escleródios \\
\cline { 2 - 3 } Extrato aquoso & & $\%$ \\
\cline { 2 - 3 } & 12 horas & 14 dias \\
\hline Stylosanthes sp. - planta inteira & $11,25 \mathrm{a}$ & $11,25 \mathrm{a}$ \\
Pennisetum glaucum folha & $50,00 \mathrm{~b}$ & $50,00 \mathrm{~b}$ \\
Pennisetum glaucum haste & $47,00 \mathrm{~b}$ & $47,00 \mathrm{~b}$ \\
Brachiaria ruzizienzis folha & $48,50 \mathrm{~b}$ & $48,50 \mathrm{~b}$ \\
Brachiaria ruzizienzis haste & $47,00 \mathrm{~b}$ & $47,00 \mathrm{~b}$ \\
Panicum maximum cv. mombaça folha & $47,00 \mathrm{~b}$ & $47,00 \mathrm{~b}$ \\
Panicum maximum cv. mombaça haste & $47,00 \mathrm{~b}$ & $47,00 \mathrm{~b}$ \\
Crotalaria juncea folha & $47,00 \mathrm{~b}$ & $47,00 \mathrm{~b}$ \\
Crotalaria juncea haste & $47,00 \mathrm{~b}$ & $47,00 \mathrm{~b}$ \\
Cajanus cajan folha & $47,00 \mathrm{~b}$ & $47,00 \mathrm{~b}$ \\
Cajanus cajan haste & $47,00 \mathrm{~b}$ & $47,00 \mathrm{~b}$ \\
Testemunha & $9,50 \mathrm{a}$ & $9,50 \mathrm{a}$ \\
\hline CV & & 8,08 \\
\hline Medias seguidas da ma
\end{tabular}

Médias seguidas da mesma letra não diferem entre si, pelo teste de Tukey, a 5\% de probabilidade.

Tabela 3 - Efeito dos extratos das plantas de cobertura sobre a formação de apotécios, em função dos dias após a instalação do experimento.

\begin{tabular}{|c|c|c|c|c|}
\hline \multirow{3}{*}{ Extrato aquoso } & \multicolumn{4}{|c|}{ Número de apotécios germinados } \\
\hline & \multicolumn{4}{|c|}{ Dias após a instalação } \\
\hline & 30 & 37 & 45 & 59 \\
\hline Stylosanthes sp. - planta inteira & $0,75^{\mathrm{ns}}$ & $9,75^{\text {ns }}$ & $16,00 \mathrm{~b}$ & $6,75^{\mathrm{ns}}$ \\
\hline Pennisetum glaucum folha & 1,50 & 9,75 & $17,50 \mathrm{~b}$ & 6,50 \\
\hline Pennisetum glaucum haste & 2,00 & 10,75 & $18,75 b$ & 7,75 \\
\hline Brachiaria ruzizienzis folha & 3,25 & 11,50 & $17,25 b$ & 5,25 \\
\hline Brachiaria ruzizienzis haste & 0,25 & 3,00 & $10,25 b$ & 6,25 \\
\hline Panicum maximum cv. mombaça folha & 1,50 & 9,75 & $19,75 b$ & 12,00 \\
\hline Panicum maximumi cv. mombaça haste & 1,00 & 12,50 & $15,00 \mathrm{~b}$ & 5,75 \\
\hline Crotalaria juncea folha & 1,00 & 7,50 & $13,75 b$ & 12,00 \\
\hline Crotalaria juncea haste & 1,25 & 7,00 & $15,75 b$ & 12,25 \\
\hline Cajanus cajan folha & 1,50 & 4,25 & $6,75 a$ & 3,00 \\
\hline Cajanus cajan haste & 0,75 & 7,50 & $16,25 b$ & 7,75 \\
\hline Testemunha & 2,25 & 11,50 & $24,00 \mathrm{~b}$ & 13,50 \\
\hline $\mathrm{CV}$ & \multicolumn{4}{|c|}{38,37} \\
\hline
\end{tabular}

Médias seguidas da mesma letra não diferem entre si, pelo teste de Scott-Knot, a 5\% de probabilidade. ${ }^{\text {ns: }}$ não significativo a $5 \%$ de probabilidade. 
Segundo FERRAz et al. (1999), é possível reduzir a emissão de apotécios com uso de fitomassa para a cobertura do solo. O elevado coeficiente de variação pode estar relacionado ao fato de que não existe um número determinado de apotécios que um escleródio pode produzir como observado por KoHN (1979), o qual pode germinar de forma carpogênica com a produção de um a vários apotécios. Na análise de regressão não foi encontrado nenhum ajuste que permita explicar os dados na interação entre os extratos aquosos e dias após a instalação do experimento.

Os resultados quanto ao número de escleródios germinados de forma carpogênica seguiram a tendência em relação ao número de apotécios germinados (Tabela 4). Com base nos resultados, é possível afirmar que a presença de extratos vegetais não afeta o número de escleródios germinados de forma carpogênica. No entanto, é importante considerar que pode ter sido pequeno o período de exposição dos escleródios a estes extratos.
No entanto, o efeito benéfico de algumas plantas de cobertura pode ser atribuído à fitomassa, como mostram Görgen et al. (2009) com a fitomassa de $B$. ruziziensis, sendo uma barreira física eficiente na redução da produção de apotécios. Görgen et al. (2010) afirmaram também que a germinação de escleródios e a formação de apotécios são, em geral, maiores durante o crescimento vegetativo da $B$. ruzizienzis em comparação ao da soja.

$\mathrm{Na}$ análise de regressão foram encontrados ajustes, que permitem explicar os dados na interação entre os extratos aquosos e dias após a instalação do experimento apenas para os extratos de P. glaucum, B. ruzizienzis e C. juncea (Fig. 2). Para os demais extratos a análise de regressão não foi significativa. A maior germinação dos escleródios ocorreu aos 45 dias e 59 dias para os extratos de $P$. glaucum (folha) e B. ruzizienzis (folha), e C. juncea (haste), respectivamente.
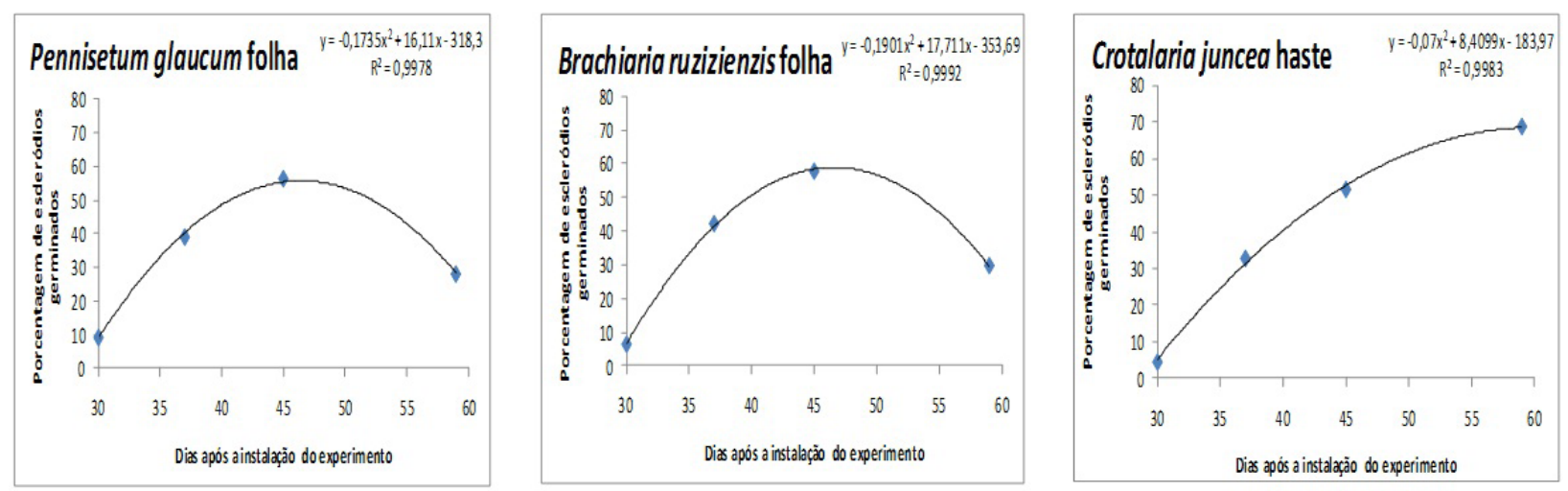

Fig. 2 - Porcentagem de escleródios germinados carpogenicamente sob a influência dos extratos vegetais em função do tempo.

Tabela 4 - Porcentagem de escleródios germinados carpogenicamente, em função dos extratos vegetais.

\begin{tabular}{|c|c|c|c|c|}
\hline \multirow{3}{*}{ Extratos aquosos } & \multicolumn{4}{|c|}{ Porcentagem de escleródios germinados } \\
\hline & \multicolumn{4}{|c|}{ Dias após a instalação } \\
\hline & 30 & 37 & 45 & 59 \\
\hline Stylosanthes sp. & $3,12^{\text {ns }}$ & $32,81^{\mathrm{ns}}$ & $54,69 \mathrm{~b}$ & $18,75 b$ \\
\hline Pennisetum glaucum folha & 9,37 & 39,05 & $56,25 b$ & $28,12 b$ \\
\hline Pennisetum glaucum haste & 9,38 & 42,19 & $64,06 \mathrm{~b}$ & $23,48 b$ \\
\hline Brachiaria ruzizienzis folha & 6,25 & 42,19 & $57,81 b$ & $29,69 b$ \\
\hline Brachiaria ruzizienzis haste & 1,56 & 17,19 & $40,62 b$ & $26,56 b$ \\
\hline Panicum maximum cv. mombaça folha & 7,81 & 31,25 & $57,81 b$ & $50,00 b$ \\
\hline Panicum maximum cv. mombaça haste & 4,69 & 48,44 & $60,94 b$ & $26,56 b$ \\
\hline Crotalaria juncea folha & 6,25 & 26,56 & $53,12 b$ & $50,00 \mathrm{~b}$ \\
\hline Crotalaria juncea haste & 4,69 & 32,81 & $51,56 b$ & $68,63 b$ \\
\hline Cajanus cajan folha & 6,25 & 17,19 & $28,10 \mathrm{a}$ & $12,50 \mathrm{a}$ \\
\hline Cajanus cajan haste & 1,56 & 28,13 & $59,37 \mathrm{~b}$ & $26,56 b$ \\
\hline Testemunha & 7,81 & 37,50 & $81,25 b$ & $59,38 b$ \\
\hline $\mathrm{CV}$ & \multicolumn{4}{|c|}{30,94} \\
\hline
\end{tabular}

Médias seguidas da mesma letra não diferem entre si, pelo teste de Scott-Knot, a 5\% de probabilidade. ${ }^{\text {ns: }}$ não significativo a $5 \%$ de probabilidade. 
O início da germinação dos ascósporos ocorreu duas horas e trinta minutos após a instalação do experimento. Os extratos das plantas de cobertura, em todas as concentrações, não diferiram em relação à testemunha, quando adicionado sulfato de streptomicina (Tabela 5).

Embora não tenham apresentado diferença entre si quanto à germinação, foi possível observar a tendência de maior crescimento micelial às 48 horas nos tratamentos com extratos de $P$. glaucum, $B$. ruzizienzis e C. cajan em relação à testemunha. Neste caso, é provável que esses extratos sirvam como substrato, reforçando a importância dos nutrientes no desenvolvimento micelial do fungo.

É importante destacar que, na avaliação quanto à germinação dos ascósporos, observou-sea presença de população bacteriana, com auxílio de um microscópio óptico, quando não foi adicionado antibiótico. Essa população foi constatada a partir dos apotécios em contato com o solo utilizados para a obtenção da suspensão de ascósporos, e apresentou potencial para reduzir a germinação dos ascósporos in vitro. Segundo FERNANDO et al. (2005), bactérias isoladas das plantas Brassica napus e Glycine max produziram compostos orgânicos voláteis capazes de inibir a germinação dos ascósporos in vitro, bem como em testes no solo. VESPERMANN et al. (2007) relataram a inibição do crescimento de $S$. sclerotiorum em $40 \%$ por isolados de bactérias. Em todas as concentrações testadas, o extrato de Stytosanthes sp. inibiu a germinação dos ascósporos por permitir o aumento da população de micro-organismos capazes de produzir substâncias nocivas ao fungo. $\mathrm{O}$ crescimento das bactérias pode ser explicado pela provável existência de compostos promotores ao desenvolvimento desses organismos antagonistas. Segundo KENNEDY (1999), as bactérias produzem metabólitoscapazes deinibirocrescimento de outros micro-organismos.

Tabela 5 - Porcentagem de germinação dos ascósporos, em função dos extratos das plantas de cobertura com e sem adição de sulfato de streptomicina.

\begin{tabular}{|c|c|c|c|c|}
\hline \multirow{3}{*}{ Extratos aquosos } & \multicolumn{4}{|c|}{ Com adição de antibiótico } \\
\hline & \multicolumn{4}{|c|}{24 horas } \\
\hline & $1 \%$ & $5 \%$ & $10 \%$ & $25 \%$ \\
\hline Stylosanthes sp. & $95^{\mathrm{ns}}$ & $96^{\text {ns }}$ & $97^{\mathrm{ns}}$ & $97^{\mathrm{ns}}$ \\
\hline Pennisetum glaucum & 95 & 96 & 97 & 97 \\
\hline Brachiaria ruzizienzis & 98 & 97 & 98 & 98 \\
\hline Panicum maximum cv. mombaça & 97 & 96 & 96 & 98 \\
\hline Crotalaria juncea & 100 & 100 & 96 & 99 \\
\hline Cajanus cajan & 95 & 96 & 96 & 97 \\
\hline Testemunha & 98 & 97 & 96 & 95 \\
\hline \multirow[t]{4}{*}{$\mathrm{CV}$} & \multicolumn{4}{|c|}{1,24} \\
\hline & \multicolumn{4}{|c|}{24 horas } \\
\hline & \multicolumn{4}{|c|}{ Sem adição de antibiótico } \\
\hline & $43 a$ & $36 a$ & $29 a$ & $23 a$ \\
\hline Pennisetum glaucum & $99,25 c$ & $100 c$ & $100 c$ & $100 c$ \\
\hline Brachiaria ruzizienzis & $100 c$ & $100 c$ & $100 c$ & $100 c$ \\
\hline Panicum maximum cv. mombaça & $100 c$ & $100 c$ & $100 c$ & $100 c$ \\
\hline Crotalaria juncea & $100 c$ & $100 c$ & $100 c$ & $100 c$ \\
\hline Cajanus cajan & $100 c$ & $100 \mathrm{c}$ & $100 \mathrm{c}$ & $100 c$ \\
\hline Testemunha & $77,25 b$ & $78,00 \mathrm{~b}$ & $77,25 b$ & $79 b$ \\
\hline \multirow[t]{3}{*}{$\mathrm{CV}$} & \multicolumn{4}{|c|}{1,12} \\
\hline & \multicolumn{4}{|c|}{48 horas } \\
\hline & \multicolumn{4}{|c|}{ Sem adição de antibiótico } \\
\hline Stylosanthes sp. & $27 a$ & $27 a$ & $27,25 a$ & $27,25 a$ \\
\hline Pennisetum glaucum & $99,25 c$ & $100 c$ & $100 c$ & $100 c$ \\
\hline Brachiaria ruzizienzis & $100 c$ & $100 c$ & $100 c$ & $100 c$ \\
\hline Panicum maximum cv. mombaça & $100 \mathrm{c}$ & $100 \mathrm{c}$ & $100 \mathrm{c}$ & $100 \mathrm{c}$ \\
\hline Crotalaria juncea & $100 c$ & $100 c$ & $100 c$ & $100 c$ \\
\hline Cajanus cajan & $100 c$ & 100c & $100 \mathrm{c}$ & $100 \mathrm{c}$ \\
\hline Testemunha & $89,25 b$ & $89,25 b$ & $87,75 b$ & $88,75 b$ \\
\hline $\mathrm{CV}$ & \multicolumn{4}{|c|}{1,19} \\
\hline
\end{tabular}

Médias seguidas da mesma letra não diferem entre si, pelo teste de Scott-Knott, a 5\% de probabilidade. ${ }^{\text {ns: }}$ não significativo a $5 \%$ de probabilidade. 
Nos demais tratamentos, os extratos promoveram a indução da germinação, mesmo quando presente uma população microbiana. A população microbiana encontrava-se em menor quantidade em relação àquela observada nos tratamento com o extrato de Stylosanthes sp. Os resultados da testemunha suportam a ideia do aporte de nutrientes, já que neste tratamento obteve-se menor número de ascósporos germinados e foi observado menor crescimento micelial às 48 horas da instalação do experimento.

As análises de regressão foram significativas apenas para os tratamentos com os extratos de Stylosanthes sp. e Pennisetum glaucum (Fig. 3).

No tratamento com a adição de antibiótico, a germinação dos ascósporos obteve relação direta com o aumento na concentração desses extratos, os quais obtiveram a maior taxa de germinação na concentração de $25 \%$. Ao adicionar o antibiótico nos tratamentos o único extrato, cuja regressão se mostrou significativa, foi para o tratamento com o extrato de Stylosanthes sp.

Com adição do antibiótico, a germinação dos ascósporos não foi impedida pela presença dos extratos. Porém, quando não foi adicionado o antibiótico, foi observado que quanto maior a concentração do extrato menor era a porcentagem de germinação. É possível afirmar que esse extrato tenha fatores de crescimento abundantes para permitir o aumento na população bacteriana, sendo mais evidente na concentração de $25 \%$.

\section{CONCLUSÕES}

Na concentração em $25 \%$ o extrato de Stylosantes sp. controla o desenvolvimento micelial de Sclerotinia sclerotiorum em meio BDA;

Com exceção do extrato de Stylosantes sp., os extratos de Crotalaria juncea, Brachiaria ruziziensis, Panicum maximumcv. mombaça, Pennisetum glaucum, Cajanus cajan servem como substrato ao desenvolvimento do fungo in vitro;

Os extratos das plantas de cobertura nas concentrações utilizadas não influenciam a germinação carpogênica e o número de apotécios formados;

O extrato da planta de Styloshantes sp. promove a redução na germinação dos ascósporos por proporcionar o aumento de bacterias associadas ao apotécio, quando não há a utilização de antibiótico.
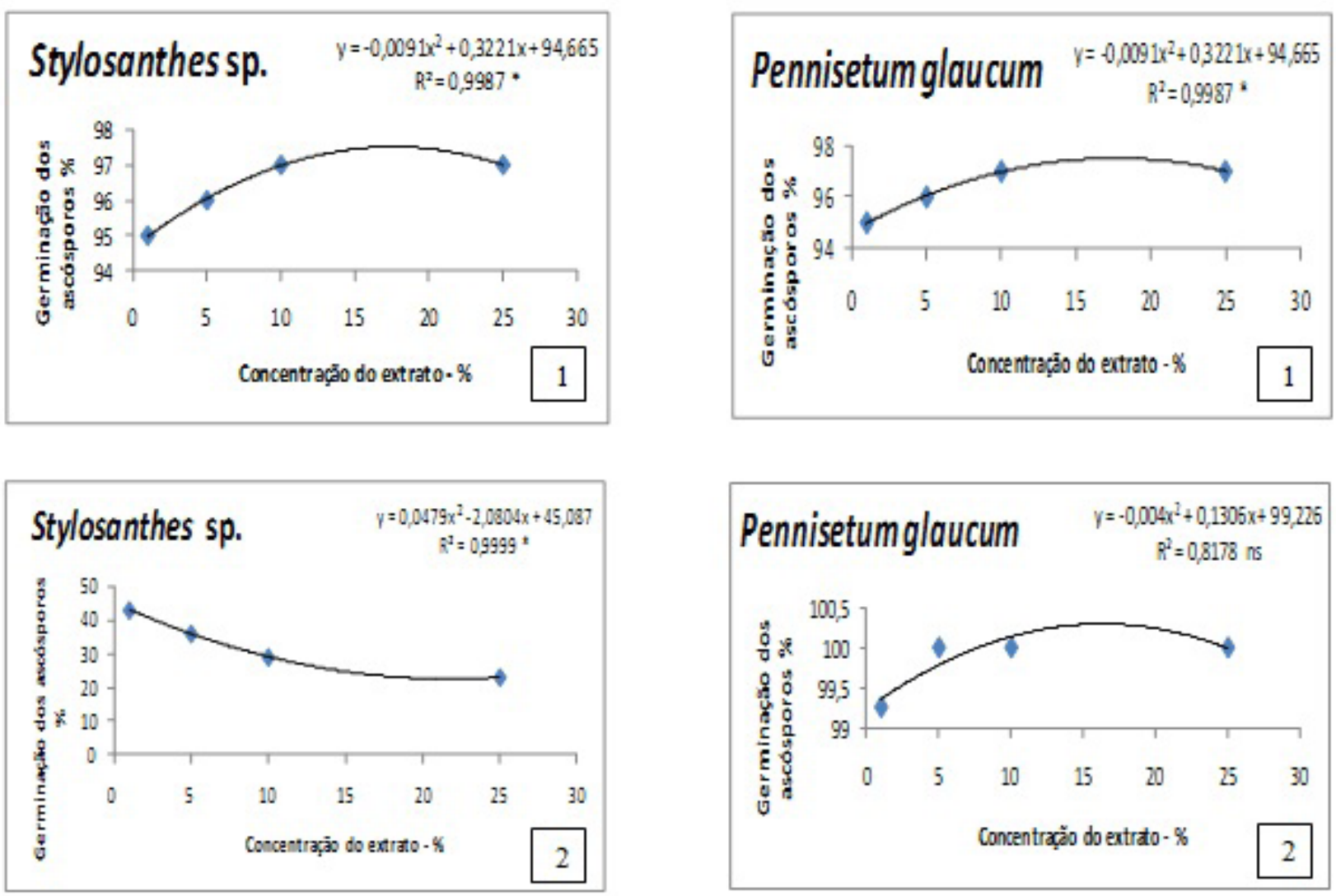

Fig. 3 - Extratos das plantas de cobertura em diferentes concentrações sobre a germinação dos ascósporos Sclerotinia sclerotiorum: 1 - com adição de antibiótico 24 horas após a inoculação, sem adição de antibiótico 48 horas após a inocu-

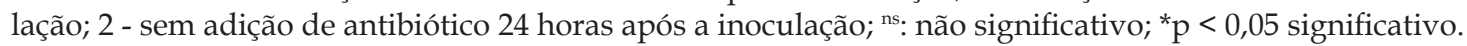




\section{AGRADECIMENTO}

À Coordenação de Aperfeiçoamento de Pessoal de Nível Superior (Capes), pela concessão da bolsa de estudos.

\section{REFERÊNCIAS}

ADAMS, P. B.; AYERS, W. A. Ecology of Sclerotinia species. Phytopatlology, v.69, n.8, p.896-899, 1979.

ASIRIFI, K.N.; MORGAN, W.C.; PARBERY, D.G. Supression of Sclerotinia soft rot of lettuce with organic soil amendments. Australian Journal of Experimental Agriculture, v.34, n.1, p.131-136, 1994.

BOLAND, G.J.; RALL, R. Index of plant hosts of Sclerotinia sclerotiorum. Canadian Journal of Plant Pathology, v.16, n.2, p.93-108, 1994.

COSTA, J.G.C.; RAVA, C.A. Influência da braquiária no manejo de doenças do feijoeiro com origem no solo. In: KLUTHCOUSKI, J.; STONE, L. F.; AIDAR, H. Integração lavoura-pecuária. Santo Antônio de Goiás: EMBRAPA Arroz e Feijão, 2003. p.523-533.

DUBEY, N.K.; KISHORE, N.; SRIVASTAVA, O.P.; DIKSHIT, A.; SINGH, S.K. Fungitoxicity of some higher plants against Rhizoctonia solani. Plant and Soil, v.72, n.1, p.91-94, 1983.

EMBRAPA (Brasil). Pesquisa estuda manejo para controle do mofo branco. Brasília, 2010. Disponível em: <http:/ / www.embrapa.br/imprensa/noticias/2010/janeiro/2a-semana/embrapa-estuda-manejo-para-controle-do-mofo-branco>. Acesso em: 20 jun. 2010.

FERNANDO, W.G.D.; RAMARATHNAM, R.; KRISHNAMOORTHY, A.S.; SAVCHUK, S.C. Identification and use of potential bacterial organic antifungal volatiles in biocontrol. Soil Biology \& Biochemistry, v.37, p.955-964, 2005.

FERRAZ, L.C.L.; CAFÉ-FILHO, A.C.; NASSER, L.C.B.; AZEVEDO, J.A. Effects of soil moisture, organic matter and grass mulching on the carpogenic germination of sclerotia and infection of bean by Sclerotinia sclerotiorum. Plant Pathology, v.48, p.77-82, 1999.

FERREIRA, D.F. Sisvar versão 4.2. Lavras: DEX/UFLA, 2003.

FRANZENER, G.; MARTINEZ-FRANZENER, A.S.; STANGARLIN, J.R.; CZEPAK, M.P.; SCHWANESTRADA, K.R.F.; CRUZ, M.E.S. Atividades antibacteriana, antifúngica e indutora de fitoalexinas de hidrolatos de plantas medicinais. Semina: Ciências Agrárias, v.28, n.1, p.29-38, 2007.

GÖRGEN, C.A.; SILVEIRA NETO, A.N. da; CARNEIRO, L.C.; RAGAGNIN, V.A.; LOBO JUNIOR, M.
Controle do mofo-branco com palhada e Trichoderma harzianum 1306 em soja. Pesquisa Agropecuária Brasileira, v.44, p.1583-1590, 2009.

GÖRGEN, C.A.; CIVARDI, E.A.; RAGAGNIN, V.A.; SILVEIRA NETO, A.N.; CARNEIRO, L.C.; LOBO JUNIOR, M. Redução do inóculo inicial de Sclerotinia sclerotiorum em soja cultivada após uso do sistema Santa Fé. Pesquisa Agropecuária Brasileira, v.45, n.10, p.11021108, 2010.

HAO, J.; SUBBARAO, K.V.; KOIKE, T. Effects of broccoli rotation on Lettuce drop caused by sclerotinia minor and on the population density of sclerotia in soil. Plant Disease, v.87, n.2, p.159-166, 2003.

HUANG, H.C. Factors affecting myceliogenic germination of sclerotia of Sclerotinia sclerotiorum. Phytopathology, v.75, n.4, p.433-437, 1985.

KENNEDY, A.C. Bacterial diversity in agroecosystems. Agriculture Ecosystems and Environment, v.74, n.1/3, p.65-76, 1999.

KOHN, L. Delimitation of the economically important plant pathogenic Sclerotinia species. Phytopathology, v.69, p.881-886, 1979.

LEANDRO, L.F.S.; GLEASON, M.L.; NUTTER, F.W.; WEGULO, S.N.; DIXON, P.M. Strawberry plant extracts stimulate secondary conidiation by Colletotrichum acutatum on symptomless leaves. Phytopathology, v.93, n.10, p.1285-1291, 2003.

LOPES, E.B.; BRITO, C.H.; ALBUQUERQUE, I.C.; OLIVEIRA, A.R.R. Influência de fatores químicos do solo sobre a incidência do mal-do-Panamá na bananeira cv. Pacovan na Paraíba. Revista de Biologia e Ciências da Terra, v.8, n.1, p.100-109, 2008.

MARSCHNER, P.; YANG, C.H.; LIEBEREI, R. CROWLEY, D.E. Soil and plant specific effects on bacterial community composition in the rhizosphere. Soil Biology and Biochemistry, v.33, n.11, p.1437-1446, 2001.

MENEZES, M.; SILVA-HANLIN, D.M.W. Guia prático para fungos fitopatogênicos. Recife: UFRPE, 1997. 106p.

MILEO, L.J.; BENTES, J.L.S.; SILVA, J.F.; CHRISTOFFOLETI, P.J. Plantas de cobertura de solo como hospedeiras alternativas de Colletotrichum guaranicola. Planta Daninha, v. 24, n.4, p. 677-683, 2006.

22. OLIVEIRA, J. A. Efeito do tratamento fungicida em sementes no controle de tombamento de plântulas de pepino (Cucumis satious L.) e pimentão (Capsicum annum L.). 1991. 111 p. Dissertação (Mestrado em Fitossanidade) - Universidade Federal de Lavras, Lavras, MG.

PEREIRA NETO, J.V.; BLUM, L.E.B. Adição de palha de milheto ao solo para redução da podridão do colo em 
feijoeiro. Pesquisa Agropecuária Tropical, v.4, n.3, p.354361, 2010.

PHILLIPS, A.J.L. Carpogenic germination of sclerotia of Sclerotinia sclerotiorum: a review. Phytophylactica, v.19, p.279-283, 1987.

PINTO, C.M.F.; MAFFIA, L.A.; CASALI, V.W.D.; CARDOSO, A.A. In vitro effect of plant leaf extracts on mycelial growth and sclerotial germination of Sclerotionum cepivorum. Journal of Phytopathology, v.146, n.8/9, p.421425, 1998.

PURDY, L.H. Sclerotinia sclerotiorum: history, diseases and symptomatology, host range, geographic distribution, and impact. Phytopathology, v.69, n.8, p.875-880, 1979.

QUEIROZ, S.C.N.; COLLINS, C.H.; JARDIM, I.C.S.F. Métodos de extração e/ou concentração de compostos encontrados em fluídos biológicos para posterior determinação cromatográfica. Química Nova, v.24, n.1, p.68-76, 2001.

ROCHA, F.S.; CAMPOS, V.P.; SOUZA, R.M. Efeito de exsudatos radiculares em endósporos de Pausteria penetrans e em juvenis do Segundo estádio de Meloidogyne incognita. Fitopatologia Brasileira, v.29, n.6, p.644-650, 2004.
RODRIGUES, E.; SCHWAN-ESTRADA, K.R.F.; FIORI-TUTIDA, A.C.G.; STANGARLIN, J.R.; CRUZ, M.E.S. Fungitoxicidade, atividade elicitora de fitoalexinas e proteção de alface em sistema de cultivo orgânico contra Sclerotinia sclerotiorum pelo extrato de gengibre. Summa Phytopathologica, v.33, n.2, p.124-128, 2007.

SILVEIRA, P.M.; BRAZ, A.J.B.P.; KLIEMANN, H.J.; ZIMMERMANN, F.J.P. Acumulação de nutrientes no limbo foliar de guandu e estilosantes. Pesquisa Agropecuária Tropical, v.35, n.3, p.133-138, 2005.

SONAGLIO, D.; ORTEGA, G.G.; PETROVICK, P.R.; BASSANI, V.L. Desenvolvimento tecnológico e produção de fitoterápicos. In: SIMÕES, C.M.O.; SCHENKEL, E.P.; GOSMANN, G.; MELLO, J.C.P.; MENTZ, L.A.; PETROVICK, P.R. Farmacognosia: da planta ao medicamento. 5.ed. Porto Alegre: UFRGS; Florianópolis: UFSC, 2003. p.289-326.

VESPERMANN, A.; KAI, M.; PIECHULLA, B. Rhizobacterial volatiles affect the growth of fungi and Arabidopsis thaliana. Applied and Environmental Microbiology, v.73, n.17, p.5639-5641, 2007.

Recebido em 8/5/11

Aceito em 16/10/12 